\title{
Mathematical Model of Linear Motor Stage with Non-Linear Friction Characteristics
}

\author{
Satoshi KANEKO ${ }^{* *}$, Ryuta SATO ${ }^{* * *}$ and Masaomi TSUTSUMI ${ }^{* * * *}$ \\ **Post graduate, Tokyo University of Agriculture and Technology \\ Nakacho 2-24-16, Koganei, Tokyo, 184-8588, JAPAN \\ *** Assistant Professor, Tokyo University of Agriculture and Technology \\ ****Professor, Tokyo University of Agriculture and Technology \\ E-mail: tsutsumi@cc.tuat.ac.jp
}

\begin{abstract}
This paper proposes a mathematical model of a feed drive system consisting of a cylindrical linear motor and linear ball guides. The friction model consists of two components; a model for the relationships between displacement and friction force under microscopic motion (non-linear spring characteristic), and a model for the relationship between velocity and friction force (Stribeck curve). The non-linear spring is modeled from the results of very low frequency simple harmonic motion experiments. The Stribeck curve is modeled from the results of friction force experiments conducted for various constant velocities. The parameters in the model were derived from machine specifications of the feed drive system and experimental results. In addition, in order to account for the quantization error of the linear scale, the controller and amplifier were modeled as a discrete time system. To evaluate the proposed model, step responses and circular motion under various conditions were measured and simulated. The influence of the friction characteristics on dynamic behavior was then investigated. In the experiment, the friction characteristics were changed and compared using three greases with differing viscosities. As a result, it was confirmed that differences in grease viscosity strongly influence the damping of vibrations for the step responses. Furthermore, it was clarified that quadrant glitches do not appear in the microscopic displacement region. For many simulation results, it was verified that the proposed model accurately reflects the real behavior.
\end{abstract}

Key words: Linear Motor Stage, Linear Ball Guide, Mathematical Model, Non-Linear Friction, Friction Model

\section{Introduction}

Linear ball guides are applied to a wide variety of conventional and precision machines such as NC machine tools, semiconductor-fabrication equipments, etc. In feed drive systems employing linear motors, the friction characteristics of the linear ball guides strongly influence dynamic behavior. However, the friction characteristics of the linear ball guides are not well defined. It is well known that the friction force of the linear ball guide behaves as a spring for displacements up to a few hundred microns, and thus the relationship between displacement and friction force gives a hysteresis loop ${ }^{(1)}$. This characteristic, referred to as a non-linear spring ${ }^{(2)}$, influences the dynamic behavior of the feed drive system, especially in the region of minute displacements. Specifically, in the case of high-speed positioning, the non-linear spring characteristic generates vibration ${ }^{(3)}$. Furthermore, in response to circular motion tests, it generates the quadrant glitch which is 
associated with hysteresis ${ }^{(4) \sim(6)}$.

The friction force in linear ball guides is consistent with the Stribeck effect of sliding friction and influences the dynamic behavior of the feed drive system at very low velocities $^{(7)(8)}$. The friction characteristics depend on the lubricant viscosity, ball retainer, pre-load, and guide size ${ }^{(9)}$. Consequently, it is necessary to clarify the non-linear friction characteristics for higher contouring movement.

There has been a great deal of research conducted in relation to the modeling of non-linear friction characteristics. Fukada ${ }^{(10)}$ established that a non-linear spring characteristic exists between ball screw and nut and went on to propose an elastic-plastic model and simulation logic. Karnopp ${ }^{(11)}$ proposed a simulation model for the relationship between velocity and friction force. This model can express the actual characteristics for very low velocity. However, it does not include the influence of viscous friction. In order to properly cover sliding motion, Canudas ${ }^{(8)}$ proposed a dynamic model called the bristle model. This encompasses both the Stribeck effect and non-linear spring characteristics. In addition, Tanaka ${ }^{(12)(13)}$ proposed a method to determine the parameters for the bristle model. It was then confirmed that the real behavior under particular conditions can be expressed using a simulation model which employs the bristle model. Iwasaki ${ }^{(14)}$ modeled the non-linear friction characteristics from dynamic and static characteristics for a feed drive system consisting of a ball screw and linear ball guides. However, a mathematical model which can express the real characteristics under large displacements without changing parameters has not yet been proposed.

This paper proposes a mathematical model for a feed drive system consisting of a rod type linear motor and linear ball guides. The mathematical model was developed to accurately express the dynamic behavior. In order to evaluate the proposed model, step responses and circular motions under various experimental conditions were measured and simulated. The proposed model can simulate the step response and circular motions for various step heights, amplitudes and feed rates by appropriately adjusting the parameters. Additionally, the parameters only need one adjustment for each grease viscosity. In addition the effect of the base oil viscosity of grease on the dynamic behavior was also investigated. As a result, it was verified that the proposed model can accurately express the influence of the friction characteristics on the dynamic behavior of the feed drive system.

\section{Experimental Set-up}

Figure 1 shows the experimental set-up. It is a one-axis feed drive system consisting of a rod type linear motor, a table, a set of linear ball guides and a linear scale. This set-up is fixed to a base plate. The feed drive system is controlled by a personal computer (PC) equipped with a DSP board.

The instruction values are input to the controller from the PC, and the position of the table is detected by a $0.1 \mu \mathrm{m}$ resolution linear scale. Linear ball guides employing retainers are also used. The friction characteristics were changed by using two viscosities of grease

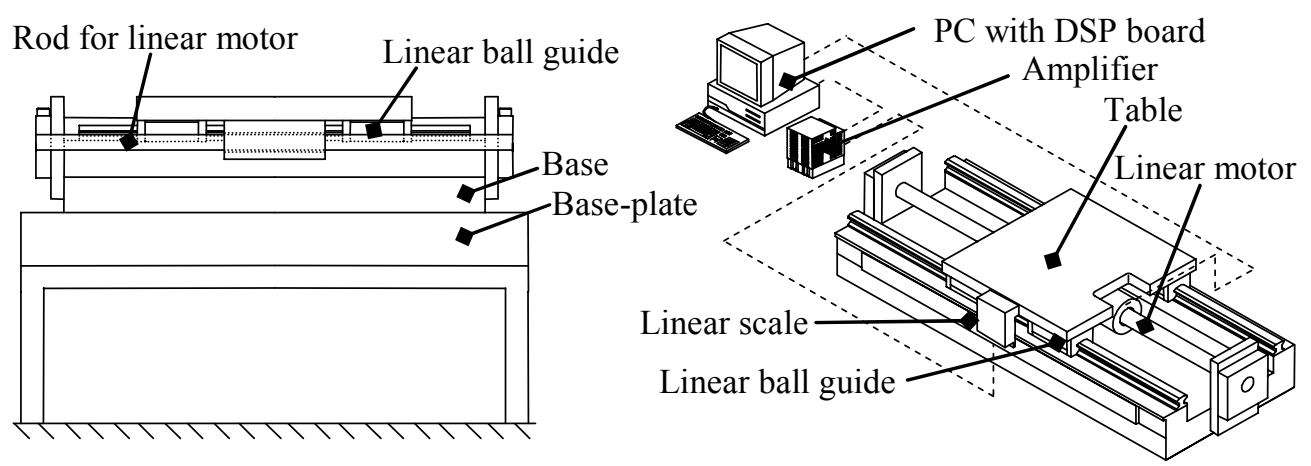

Fig. 1 Experimental set-up 
(130 cSt and $220 \mathrm{cSt}$ ). Prior to taking the first measurements, the linear ball guides were worked a little after being packed with grease.

Because the inertia force is negligible, the friction force is equivalent to the thrust instruction to the amplifier.

\section{Modeling of Feed Drive System}

Figure 2 shows a dynamic model of the experimental set-up shown in Fig. 1. The dynamic model consists of a table, a rod for linear motor and a base plate. The parameter definitions and associated values for the model are listed in Table 1. Figure 1 leads to the following equations of motion:

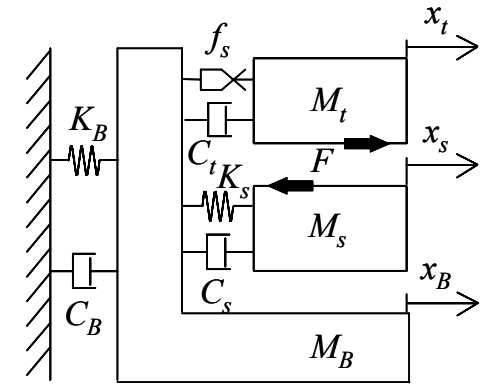

Fig. 2 Dynamic model of experimental set-up

$$
\left.\begin{array}{l}
M_{t} \ddot{x}_{t}+C_{t} \cdot\left(\dot{x}_{t}-\dot{x}_{B}\right)+f_{s}=F \\
M_{s} \ddot{x}_{s}+C_{s} \cdot\left(\dot{x}_{s}-\dot{x}_{B}\right)+K_{s} \cdot\left(x_{s}-x_{B}\right)=-F \\
M_{B} \ddot{x}_{B}+C_{B} \dot{x}_{B}+K_{B} x_{B}=C_{t} \cdot\left(\dot{x}_{t}-\dot{x}_{B}\right)+C_{s} \cdot\left(\dot{x}_{s}-\dot{x}_{B}\right)+K_{s} \cdot\left(x_{s}-x_{B}\right)+f_{s}
\end{array}\right\}
$$

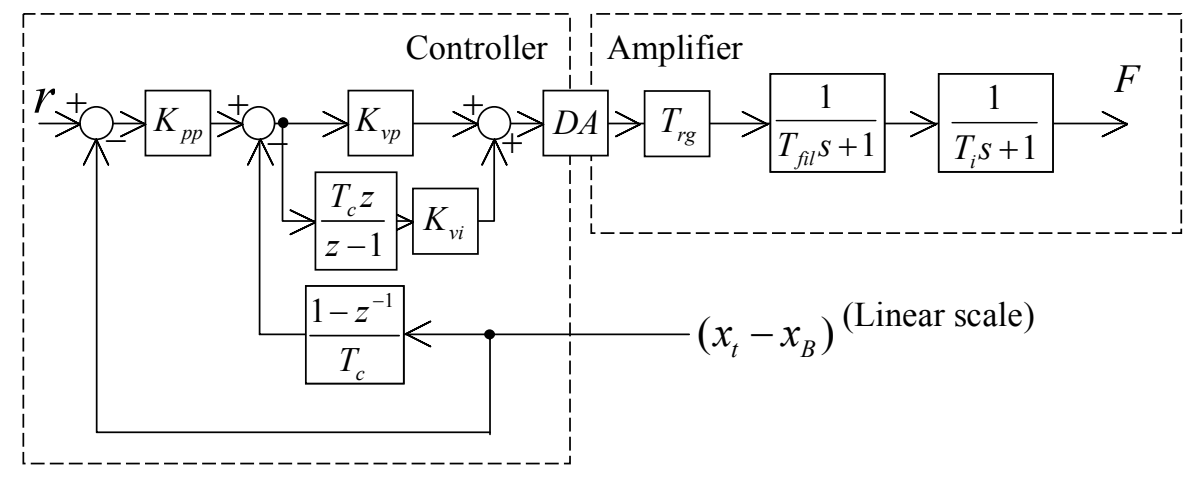

Fig. 3 Block diagram for controller and amplifier

In the experiments, the relative displacement $\left(x_{t}-x_{B}\right)$ between the table and base is detected using a $0.1 \mu \mathrm{m}$ resolution linear scale and the position of the table is digitally controlled by the PC. Therefore, when modeling the control system as a discrete-time system, it is necessary to consider the quantization error of the linear scale ${ }^{(3)}$.

The models of the controller and amplifier for the simulation are shown in Fig. 3. In this, $r$ is the reference position [m], $K_{p p}$ is the proportional gain of the position loop [1/s], $K_{v p}$ is the proportional gain of the velocity loop [s/m], $K_{v i}$ is the integral gain of the velocity loop $[1 / \mathrm{m}], T_{c}$ is the control frequency [s] (identified from experimental results of velocity step responses), $D A$ is the DA converter constant [V], $T_{r g}$ is the torque command gain $[\mathrm{Nm} / \mathrm{V}], T_{f i l}$ is the time constant of the torque instruction filter [s], and $T_{i}$ is the time constant of current control loop $[\mathrm{s}] . T_{c}$ is identified from experimental results of velocity step responses.

\section{Modeling of Non-linear Friction Characteristics}

\subsection{Relationship between velocity and friction force}

In order to investigate the effects of the velocity on the friction force, the force was measured for various constant velocities. Seventeen velocities from $6.31 \mathrm{~mm} / \mathrm{min}$ to 10,000 $\mathrm{mm} / \mathrm{min}$ were chosen. The friction force at each velocity is an average calculated by 
removing the transient response and taking the average between the two directions of the motion.

Figure 4 shows the relationship between velocity and friction force. It can be seen from this figure that the friction force takes a maximum value at very low velocities. For velocities above $0.02 \mathrm{~m} / \mathrm{s}$, the friction force linearly increases with the increasing velocity. This behavior is inherent to viscous friction. This occurs irrespective of the grease viscosity employed.

Table 1 Parameters for dynamic model

\begin{tabular}{lc|c|c}
\hline \multicolumn{1}{c|}{ Parameter } & & Unit & Value \\
\hline Mass of table & $M_{t}$ & $\mathrm{~kg}$ & 16 \\
\hline Mass of rod & $M_{s}$ & $\mathrm{~kg}$ & 2.8 \\
\hline Mass of base & $M_{B}$ & $\mathrm{~kg}$ & 319 \\
\hline Visous damping of linear ball guides & $C_{t}$ & $\mathrm{Ns} / \mathrm{m}$ & 55.5 \\
\hline Visous damping of rod and support syste & $C_{s}$ & $\mathrm{Ns} / \mathrm{m}$ & 1000 \\
\hline Visous damping of base & $C_{B}$ & $\mathrm{Ns} / \mathrm{m}$ & 1000 \\
\hline Axial stiffness at rod and sopport system & $K_{s}$ & $\mathrm{~N} / \mathrm{m}$ & $7.56 \times 10^{4}$ \\
\hline Axial stiffness at base & $K_{B}$ & $\mathrm{~N} / \mathrm{m}$ & $1.34 \times 10^{6}$ \\
\hline Friction force at linear ball guides & $f_{s}$ & $\mathrm{~N}$ & - \\
\hline Thrust of motor & $F$ & $\mathrm{~N}$ & - \\
\hline
\end{tabular}

Referring to Ref. (15), the relationship between velocity and friction force may be approximated to:

$$
f_{v}(v)=\left\{f_{s}(x)+C_{t 1} v^{\alpha} \exp \left(-\left(\frac{v}{v_{a}}\right)^{\beta}\right)\right\} \operatorname{sgn}(v)+C_{t 2} v^{\gamma}
$$

where, $f_{s}(x)$ is friction force for the non-linear spring characteristics which is a function only of displacement. Because movement is in the order of millimeters, $f_{s}(x)$ is equal to the constant friction force (Coulomb friction force).

As shown in Fig. 4, the measured friction characteristic, represented with red marks, can be fitted by adjusting the six

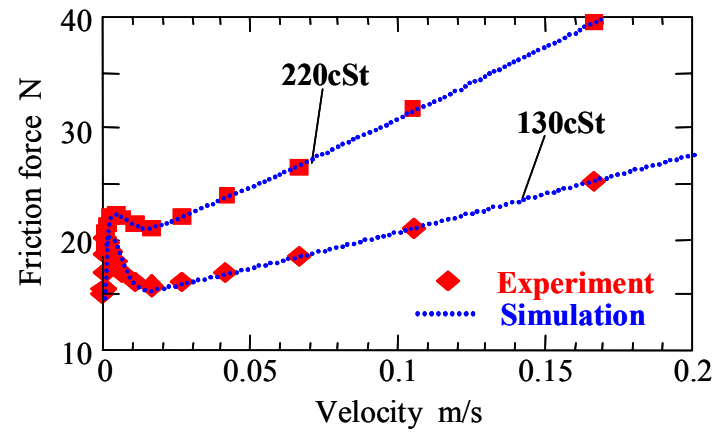

Fig. 4 Relationship between velocity and friction force parameters $\left(C_{t 1}, C_{t 2}, V_{a}, \alpha, \beta\right.$ and $\left.\gamma\right)$ in Eq. (2). The corresponding characteristic generated from Eq. (2) is plotted by a dashed blue line in the same figure. It can be seen from the figure that the simulated curves are good agreement with the measured friction characteristics. Differentiating the relationship between velocity and friction force with respect to velocity yields the viscous friction force as a function of velocity $d f(v) / d v$. For the simulation model, the coefficient of viscous damping $C_{t}$ in Eq. (1) can be replaced by $d f(v) / d v$.

\subsection{Non-linear spring characteristics}

In order to investigate the non-linear spring characteristics of the linear ball guides, the friction force was measured under simple harmonic motion of minute amplitude.

Figure 5 shows the hysteresis loops produced by the displacement and friction force. The two loops were measured, one for each grease viscosity at $250 \mu \mathrm{m}$ amplitude, $0.05 \mathrm{~Hz}$ frequency. It can be clearly seen that, up to $200 \mu \mathrm{m}$ displacement, the friction force 
non-linearly increases with increasing displacement. Above this displacement, the friction force becomes constant. This characteristic is referred to as the non-linear spring characteristic. It is important to model this characteristic in order to simulate the dynamic behavior under minute motion conditions.

In this paper, the characteristic is modeled as follows:

$$
f_{s}(x)=K(x) x
$$

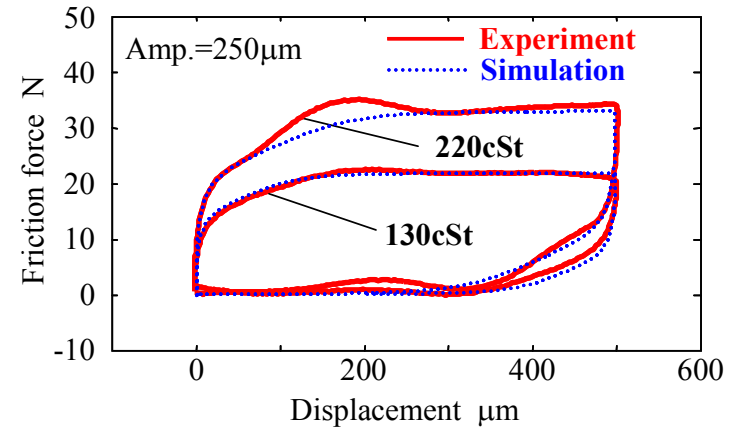

Fig. 5 Hysteresis loops of friction force due to simple harmonic vibration at very low frequency $(0.05 \mathrm{~Hz})$

where, $K(x)$ is a function of spring constant which expresses the non linear spring behavior, and $x$ is displacement.

Therefore, $K(x)$ can be expressed as follows:

$$
K(x)=\frac{K_{1}}{\left|\frac{x}{x_{1}}\right|^{a}+1}+\frac{K_{2}}{\left|\frac{x}{x_{2}}\right|^{b}+1}+\frac{K_{3}}{\left|\frac{x}{x_{3}}\right|^{c}+1}
$$

Data calculated from Eqs. (3) and (4) are also plotted in Fig. 5. This shows that the hysteresis loops can be accurately represented by adjusting the parameters $\left(x_{1}, x_{2}, x_{3}, K_{1}, K_{2}\right.$, $\left.K_{3}, a, b, c\right)$ in Eq. (4). This demonstrates the validity of the non-linear friction characteristic expressed in the simulation. It is also possible to take into account differences in the viscosity of the oil on which the grease is based.

As mentioned above, two non-linear friction characteristics which depend on velocity and displacement were modeled. Therefore, Eq. (1) can be rewritten as follows:

$$
\begin{aligned}
& M_{t} \ddot{x}_{t}+\frac{d f_{v}(v)}{d v} \cdot\left(\dot{x}_{t}-\dot{x}_{B}\right)+f_{s}(x)=F \\
& M_{s} \ddot{x}_{s}+C_{s} \cdot\left(\dot{x}_{s}-\dot{x}_{B}\right)+K_{s} \cdot\left(x_{s}-x_{B}\right)=-F \\
& M_{B} \ddot{x}_{B}+C_{B} \dot{x}_{B}+K_{B} x_{B}=\frac{d f_{v}(v)}{d v} \cdot\left(\dot{x}_{t}-\dot{x}_{B}\right) \\
& +C_{s} \cdot\left(\dot{x}_{s}-\dot{x}_{B}\right)+K_{s} \cdot\left(x_{s}-x_{B}\right)+f_{s}(x)
\end{aligned}
$$

Equation (5) includes the non-linear spring characteristics and velocity dependence.

\section{Experimental and Simulation Results}

\subsection{Step responses}

As mentioned above, mathematical models incorporating non-linear friction characteristics were developed. The parameters of the friction model were determined by trial and error in order to match the model to the experimental results (Refer to Figs. 4 and 5), as listed in Table 2. The controller servo gains are listed in Table 3.

Herein, to evaluate the proposed model, step responses were examined through experiment and simulation. All of the experiments were repeated three times to confirm the repeatability of measurement.

Figure 6 shows the simulation results in the absence of non-linear friction for a step input height of $250 \mu \mathrm{m}$. The step response curves show a damped oscillatory form. Therefore, it may be said that the non-linear spring behavior under minute motion relates to the vibration damping of the system. 
Figure 7 shows the simulation and experimental results for step responses with input heights of $250 \mu \mathrm{m}$ and $100 \mu \mathrm{m}$. Figures 7(a) and (b) show the results for viscosities of 130 cSt and $220 \mathrm{cSt}$, respectively. Figure 8 shows the results for step heights of $10 \mu \mathrm{m}$ and 5

Table 2 Parameters for friction model

\begin{tabular}{c|c|c|c}
\hline \multirow{2}{*}{ Parameter } & \multirow{2}{*}{ Unit } & \multicolumn{2}{|c}{ Value } \\
\cline { 3 - 4 } & & $130 \mathrm{cSt}$ & $220 \mathrm{cSt}$ \\
\hline$x_{1}$ & $\mathrm{~m}$ & $0.75 \times 10^{-6}$ & $1.1 \times 10^{-6}$ \\
\hline$x_{2}$ & $\mathrm{~m}$ & $8.0 \times 10^{-6}$ & $8.0 \times 10^{-6}$ \\
\hline$x_{3}$ & $\mathrm{~m}$ & $120 \times 10^{-6}$ & $180 \times 10^{-6}$ \\
\hline$K_{1}$ & $\mathrm{~N} / \mathrm{m}$ & $680 \times 10^{4}$ & $800 \times 10^{4}$ \\
\hline$K_{2}$ & $\mathrm{~N} / \mathrm{m}$ & $70 \times 10^{4}$ & $100 \times 10^{4}$ \\
\hline$K_{3}$ & $\mathrm{~N} / \mathrm{m}$ & $8.0 \times 10^{4}$ & $6.0 \times 10^{4}$ \\
\hline$a$ & - & 2.5 & 7 \\
\hline$b$ & - & 2 & 2 \\
\hline$c$ & - & 4 & 6 \\
\hline$C_{t 1}$ & $\mathrm{~N} / \mathrm{m}$ & 5.2 & 9 \\
\hline$C_{t 2}$ & $\mathrm{~N} / \mathrm{m}$ & 63 & 145 \\
\hline$v_{a}$ & $\mathrm{~m} / \mathrm{s}$ & $1.3 \times 10^{-2}$ & $8.0 \times 10^{-3}$ \\
\hline$\alpha$ & - & $3.0 \times 10^{-2}$ & $2.0 \times 10^{-1}$ \\
\hline$\beta$ & - & 2 & 2 \\
\hline$\gamma$ & - & 1.1 & 1.1 \\
\hline
\end{tabular}

Table 3 Parameters of servo-gains for controller

\begin{tabular}{c|c|c|c}
\hline \multirow{2}{*}{ Parameter } & \multirow{2}{*}{ Unit } & \multicolumn{2}{|c}{ Value } \\
\cline { 3 - 4 } & & Step response & Circular motion test \\
\hline$K_{p p}$ & $1 / \mathrm{s}$ & 350 & 100 \\
\hline$K_{v p}$ & $\mathrm{~s} / \mathrm{m}$ & 5 & 30 \\
\hline$K_{v i}$ & $1 / \mathrm{m}$ & 250 & 3000 \\
\hline
\end{tabular}

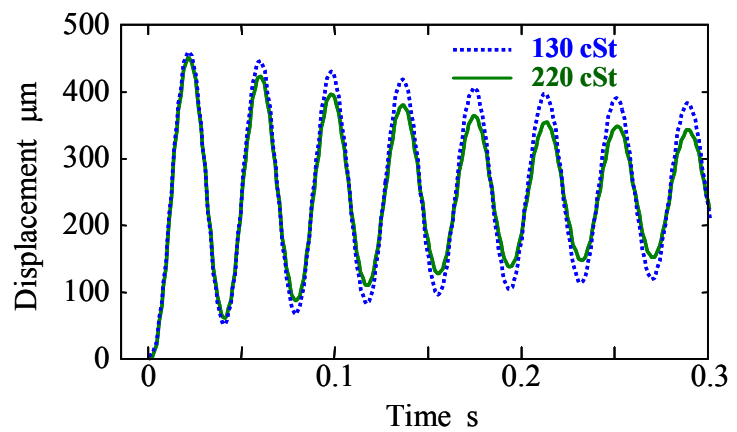

Fig. 6 Simulation results without consisting non-linear friction characteristics

$\mu \mathrm{m}$, and for the viscosities of $130 \mathrm{cSt}$ and $220 \mathrm{cSt}$, respectively.

As shown in Fig. 7, for both viscosities, the proposed model is as good a representation of the experimental results as the viscous friction model. In addition, it can be clearly seen that higher grease viscosity yields higher damping. It can be said that both models can simulate the experimental results in the range $100 \mu \mathrm{m}$ to $200 \mu \mathrm{m}$.

Referring to Fig. 8, for minute input heights, the proposed model approximately agrees with experimental results whereas the viscous friction model differs markedly. The viscous friction model yields an oscillatory response which depends on the grease viscosity. In addition, there is a very large lag in the response. This is in contrast to the close agreement between the proposed model and the experimental results.

Moreover, vibration (transient overshoot) with low frequency such as shown in Fig. 7 does not occur although the servo gain is unchanged. The velocity for the step heights shown in Fig. 8 is very low (about $0.04 \mathrm{~mm} / \mathrm{s}$ ). As shown in Fig. 4, at this very low velocity, 
the friction force is strongly non-linear. In summary, for the minute step response, the velocity dependence of the friction force and the non-linear spring characteristic governs the vibration damping of the system.

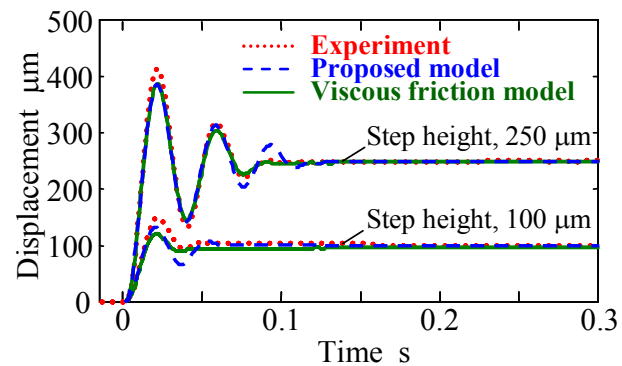

(a) $130 \mathrm{cSt}$

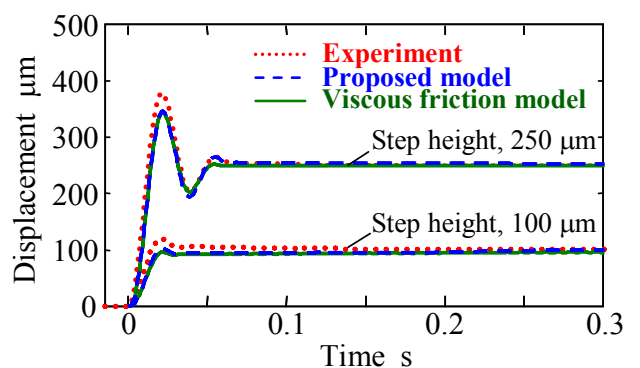

(b) $220 \mathrm{cSt}$

Fig. 7 Comparison of step responses

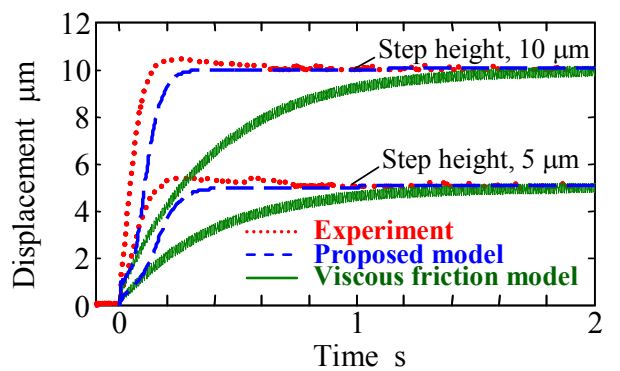

(a) $130 \mathrm{cSt}$

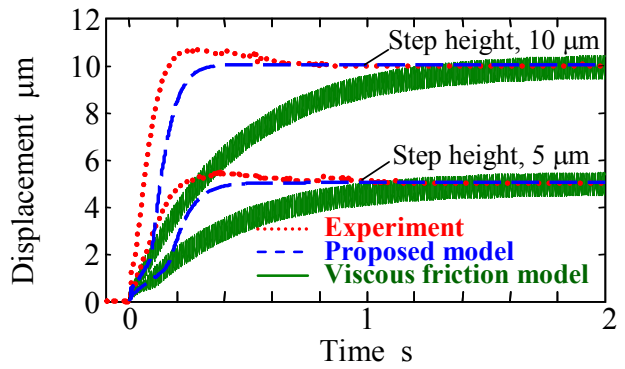

(a) $220 \mathrm{cSt}$

Fig. 8 Comparison of step responses under microscopic displacement region

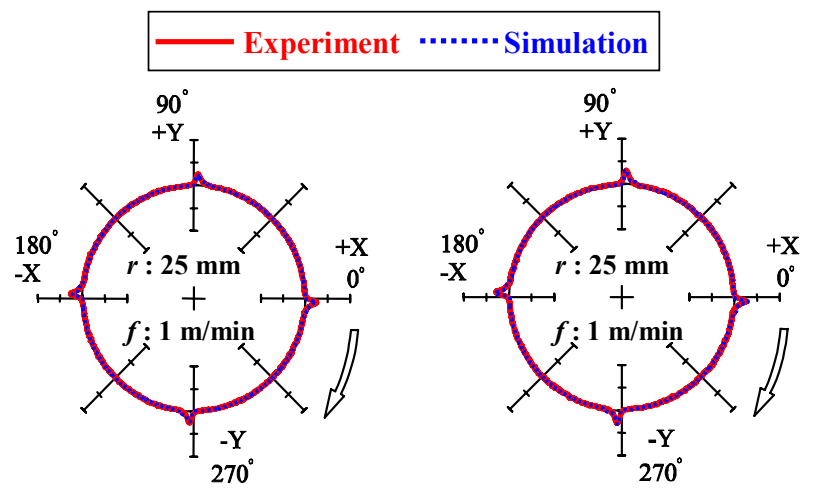

(a) $130 \mathrm{cSt}$

(b) $220 \mathrm{cSt}$

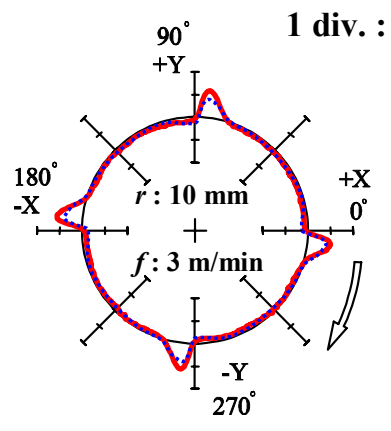

(c) $130 \mathrm{cSt}$

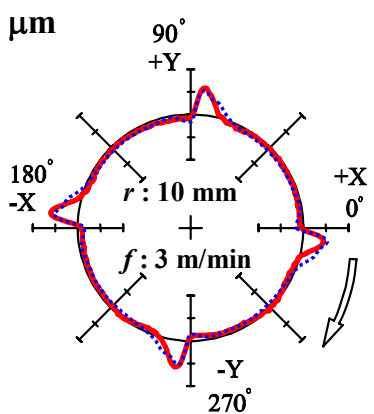

(d) $220 \mathrm{cSt}$

Fig. 9 Experimental and simulation results of circular trajectory under various conditions

\subsection{Circular motion test}

As mentioned above, the proposed model for the friction force accurately reflects the actual step responses obtained experimentally for various input heights. This type of 
response often occurs when XY tables are driven with circular motions. In order to further verify the effectiveness of the proposed model, it was applied to the case of such circular motions.

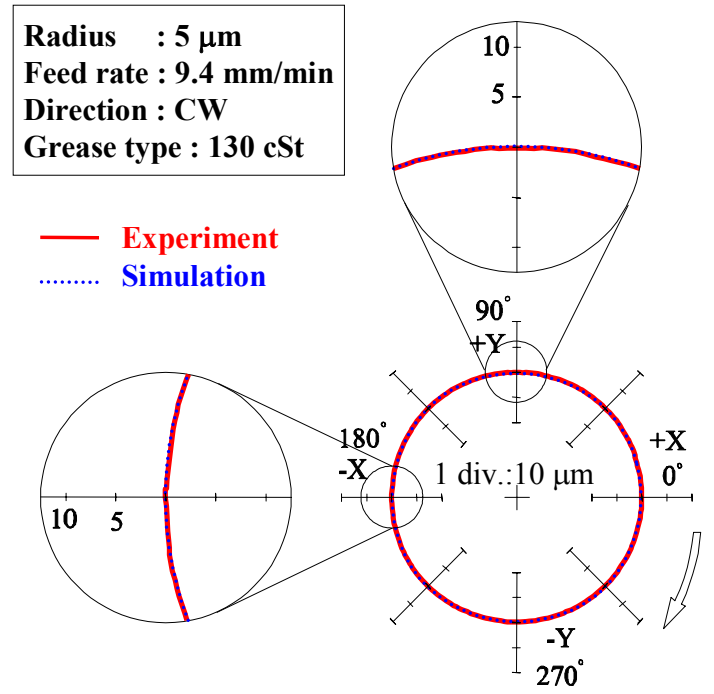

Fig. 10 Experimental and simulation results of circular trajectory in minute displacement region

For the simulation, two linear motion axes with the same characteristics were employed and a circular trajectory was generated. For the experiment, only one linear axis was used. The experimental circular trajectory was generated by combining two measured trajectories; that is, one is not shifted and the other is shifted to create a 90 degrees delay. From the circular trajectories generated by experiment and simulation, the height of the quadrant glitch was investigated in detail.

Figure 9 shows the experimental and simulated results for circular motions under various radii, feed rates and grease viscosities. As shown in Figs. 9(a) and (b), the height of the quadrant glitch changes little, even if the grease viscosity changes. As shown in Figs. 9(a) and (c), an important factor affecting the height of quadrant glitch is the centripetal acceleration; the higher the acceleration, the larger the quadrant glitch. These characteristics are accurately reflected by the proposed model for various conditions.

The experiments went on to evaluate the proposed model in the minute displacement region. In this region, the non-linear spring characteristic is dominant. Figure 10 shows the experimental and simulated results for a circular trajectory in the minute region. Quadrant glitches are conspicuously absent. It follows that the non-linear friction characteristic does not affect the generation of quadrant glitches in the minute displacement region.

Figure 11 shows the relationships between the centripetal acceleration and the quadrant glitch height. Twelve centripetal accelerations were chosen within the various radii and feed rates. The quadrant glitch heights were determined at 90 and 180 degrees. The value at 90 degrees is defined by maximum radius in the range from 10 to 90 degrees. The value at 180 degrees is defined by maximum radius in the range from 100 to 180 degrees.

It can be seen that the quadrant glitch grows with increasing acceleration up to $0.3 \mathrm{~m} / \mathrm{s}^{2}$. Subsequently, it settles to a constant value. This characteristic is reflected well in the simulated results. However, the actual measured height of the quadrant glitch is higher than that simulated.

Figure 12 shows the relationship between the radius of the circular motion and the quadrant glitch height. The acceleration was maintained at $0.2 \mathrm{~m} / \mathrm{s}^{2}$. All experiments and simulations were conducted using identical servo gains. It can be seen that the quadrant glitch height reduces with decreasing radius. Again, this behavior is reflected well in the simulated results.

From the experimental and simulated results, it can be concluded that the proposed 
mathematical model accurately reflects various motions of feed drive systems that are driven by linear motors and supported by ball guides with retainers.

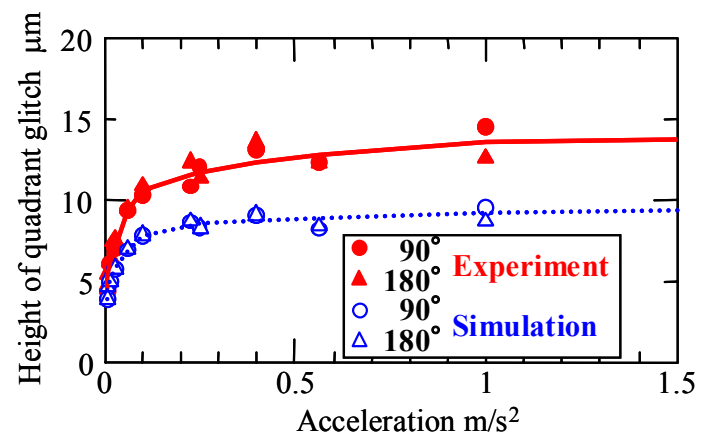

Fig. 11 Influence of centrifugal acceleration on quadrant glitch

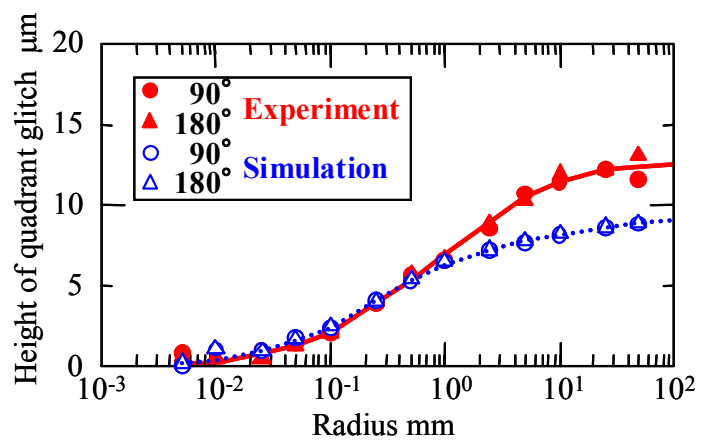

Fig. 12 Influence of radius of circular motion on quadrant glitch

\section{Conclusions}

In this paper, mathematical models for feed drive systems in the minute displacement region were discussed. In particular, non-linear spring characteristics were experimentally investigated in detail. Based on the experimental results, a new non-linear friction model was proposed. The following conclusions were obtained:

(1) The proposed non-linear friction model can be used to accurately simulate the friction characteristics of the experimental set-up.

(2) The proposed mathematical model yields the correct step response behavior under various step heights in the minute displacement region.

(3) The quadrant glitch height for circular motion can be simulated for various radii and feed rates.

(4) Circular motion in minute displacement region does not generate quadrant glitches.

(5) The proposed model reflects the tendency of quadrant glitch height to increase with increasing radius of motion.

The proposed mathematical model can express the real behavior of a feed system that is driven by a linear motor. Thus, it can be an effective tool for designing the mechanism and controller. The relation between the friction characteristics and the vibration damping of the system will be analyzed using this model.

\section{Acknowledgement}

The authors would like to express their thanks to THK Co. Ltd. who kindly provided the experimental set-up and linear ball guides.

\section{References}

(1) S. Futami, A. Furutani, Nanometer Positioning Using AC Linear Motor and Rolling Guide (2nd Report) -Tribology of the Rolling Guide-, Journal of the Japan Society for Precision 
Engineering, Vol. 57, No. 10, (1991), pp. 1808-1813 (in Japanese).

(2) J. Otsuka, I. Aoki, T. Ishikawa, A Study on Nonlinear Spring Behavior of Rolling Elements (1st Report) -Two Simple Measuring Methods-, Journal of the Japan Society for Precision Engineering, Vol. 66, No. 6, (2000), pp. $944-949$ (in Japanese).

(3) S. Makinouchi, Y. Hayashi, S. Kamiya, New Stage System for Step-and-Repeat Scanning Stepper, Journal of the Japan Society for Precision Engineering, Vol. 61, No. 12, (1995), pp. 1676-1680 (in Japanese).

(4) S. Hayama, M. Ito, N. Ootake, J. Fujita, T. Kurokawa, Y. Kakino, A Study of the Generation Mechanism and the Compensation of the Exponential Type Lost Motion for Feed Drive System of NC Machine Tools, Journal of the Japan Society for Precision Engineering, Vol. 62, No. 2, (1996), pp. 247-251 (in Japanese).

(5) K. Miyaguti, M. Ninomiya, Y. Watanabe, S. Arai, M. Hamamura, Y. Kakino, A Study on the Friction Torque Variation of a Ball Screw at Motion Direction Change (1st Report) Friction Torque Variation due to the Change in Ball Contact Points - , Journal of the Japan Society for Precision Engineering, Vol. 68, No. 6, (2002), pp. 833-836 (in Japanese).

(6) M. Hamamura, J. Fujita, K. Miyaguti, Y. Watanabe, Y. Kakino, A. Matsubara, A Study on the Friction Torque Variation of a Ball Screw at Motion Direction Change (2nd Report) Friction Torque Variation due to the Change in Ball Contact Points - , Journal of the Japan Society for Precision Engineering, Vol. 69, No. 5, (2003), pp. 726-730 (in Japanese).

(7) K. Tsuruta, T. Murakami, S. Futami, Nonlinear Friction Behavior of Discontinuity at Stroke End in a Ball Guide Way, Journal of the Japan Society for Precision Engineering, Vol. 69, No. 12, (2003), pp. 1759-1763 (in Japanese).

(8) C. Canudas de Wit, H. Olsson, K. J. Astrom and P. Lischinsky, A New Model for Control of System with Friction, IEEE Transactions Automatic Control, Vol. 40, No. 3, (1995), pp. 419-425.

(9) R. Sato, M. Tsutsumi, D. Imaki, Experimental Evaluation on the Friction Characteristics of Linear Ball Guides, Journal of the Japan Society for Mechanical Engineering, Series C, Vol. 73, No. 10, (2007), pp. 2811-2819 (in Japanese).

(10) S. Fukada, Experiment and Simulation for Microscopic Behavior of Ball Screw, Technical Committee of Ultra Precision Positioning, No. 3, (2005), pp. 7-16 (in Japanese).

(11) D. Karnopp, Computer Simulation of Stick-Slip Friction in Mechanical Dynamic Systems, Transaction of ASME, Jounral of Dynamic System, Measurement and Control, Vol. 107, (1985), pp. 100-103.

(12) T. Tanaka, T. Oiwa, J. Otsuka, Study on Friction Model of Linear Ball Guideway for Precision positioning, Journal of the Japan Society for Precision Engineering, Vol. 72, No. 4, (2006), pp. 470-474 (in Japanese).

(13) T. Tanaka, T. Oiwa, J. Otsuka, Study on Friction Model of Linear Ball Guideway for Precision positioning Control (2nd Report) -Simulation of Full-closed Loop Control Using Bristle Model-, Journal of the Japan Society for Precision Engineering, Vol. 73, No. 4, (2007), pp. 465-469 (in Japanese).

(14) M. Iwasaki, Y. Maeda, M. Kawafuku, H. Hirai, Improvement of Precise Positioning Performance by Modeling and Compensation for Nonlinear Friction, IEEJ Trans. IA, Vol. 126, No. 6, (2006), pp. 732-740 (in Japanese).

(15) R. Sato, M. Tsutsumi, H. Arihara, Controller Design Method for Feed Drive Systems Considering Control Frequency, Proceedings of the Annual Conference of the Japan Society for Precision Engineering in Autumn, (2006), pp. 867-868 (in Japanese). 